\title{
Anterior glenohumeral dislocations: what to do and how to do it
}

\author{
A P Gleeson
}

Anterior glenohumeral dislocation is the commonest major joint dislocation seen in the accident and emergency (A\&E) department. ${ }^{1}$ There is, however, no uniform agreement on which form of analgesia should be given before reduction, nor on the reduction manoeuvre of choice. In this review I shall outline the common approaches to shoulder dislocation reduction, attempt to dispel some common misconceptions about the condition, and set out a logical management strategy.

\section{Patient assessment}

HISTORY

Anterior glenohumeral dislocations occur when the arm is forcibly abducted and externally rotated, the majority of patients sustaining this injury in a fall. The two groups most commonly afflicted by shoulder dislocations are the young sporting male and the elderly female. ${ }^{2}$

The history should encompass questions about past medical history, medications, allergies and, if intravenous sedation/analgesia is to be given, when the patient last ate or drank.

\section{EXAMINATION}

Anterior dislocations can usually be recognised by the lack of the normal convex contour of the lateral aspect of the shoulder but this vital clue may be absent in obese patients and those with fracture-dislocations. Sensation in the arm, particularly in the area supplied by the axillary nerve, should be assessed before reduction as traction reduction manoeuvres may cause stretching of nerve trunks with resultant neurapraxias. Distal pulses should also be sought and, if absent, a precipitous reduction following radiological confirmation of the dislocation is of the utmost importance. Patients with a significant history of cardiorespiratory disease should have both of these systems examined clinically, particularly if they are to be given intravenous medication.

\section{RADIOGRAPHIC FEATURES}

Accident and Emergency Department, St George's Healthcare NHS Trust, Blackshaw Road, London SW17 OQT, UK

A P Gleeson

Correspondence to: A P Gleeson, Consultant in Accident and Emergency Medicine.

Accepted for publication 21 July 1997
An anteroposterior radiograph of the shoulder alone will normally show an anterior dislocation but axillary or trans-scapular views are usually performed in addition. Anterior glenohumeral dislocations can be classified according to the position of the humeral head (fig 1): (a) subcoracoid; (b) subglenoid; (c) luxatio erecta; (d) subclavicular; (e) supraglenoid; (f) intrathoracic; (g) fracture-dislocation.

This classification is very important as, contrary to popular opinion, ${ }^{3}$ different reduction manoeuvres or variations on a particular manoeuvre are required for different dislocations.

\section{Treatment}

\section{ANALGESIA}

Despite the considerable pain associated with this injury there is a vogue for reducing dislocations without any analgesia. This practice has evolved mainly for the convenience of the physician. It requires only one operator, monitoring is not mandatory, and once reduction has been effected the patient can be discharged promptly from A\&E. ${ }^{4-8}$ A few patients will tolerate reduction without analgesia, but they are in the minority and must be carefully selected. Patient comfort is paramount and should not be compromised by a need to increase patient turnover in $\mathrm{A} \& \mathrm{E}$.

There are several options for pain control available to the emergency physician. Entonox is widely used as the sole means of analgesia during reduction, ${ }^{79}$ but elderly patients in particular have difficulty using it effectively. An excellent alternative is to deliver the $\mathrm{N}_{2} \mathrm{O}: \mathrm{O}_{2}$ mixture through an anaesthetic circuit using flow meters, as no effort is required on the part of the patient to ensure delivery of the mixture. Regional anaesthesia-that is, suprascapular $^{1011}$ and interscalene brachial plexus blocks, ${ }^{12}$-has been used with moderately good results. Intra-articular lignocaine has also recently been shown to be as effective as intravenous sedation/analgesia. ${ }^{13} 14$ Intravenous benzodiazepine and opioid ensures good analgesia and relaxation and is currently the gold standard. It must be stressed, however, that all patients given intravenous sedation must be monitored with ECG and pulse oximetry, at a minimum, in an area where resuscitation equipment is at hand. Two doctors must be in attendance, one of whom is trained in advanced resuscitation and airway management. ${ }^{15}$ General anaesthesia is generally reserved for cases where reduction manoeuvres have failed using the above analgesic techniques, or when open reduction and internal fixation are primarily indicated, as with certain fracture-dislocations. ${ }^{16}$

\section{REDUCTION MANOEUVRES}

A multitude of different reduction manoeuvres have been described. They can be divided into traction and leverage techniques.

The Hippocratic method is the earliest described traction technique. ${ }^{3}$ Stimson ${ }^{17}{ }^{18}$ required the patient to be prone, using a weight tied around the wrist to apply traction. Lacey and Crawford, ${ }^{19}$ and later McNair, ${ }^{20}$ employed manual traction, external rotation, elevation of the arm, and pressure over the humeral head with the patient prone, that is, a modification of the Milch manoeuvre. Pick ${ }^{21}$ and Lippert ${ }^{22}$ used manual traction with elbow flexion to 

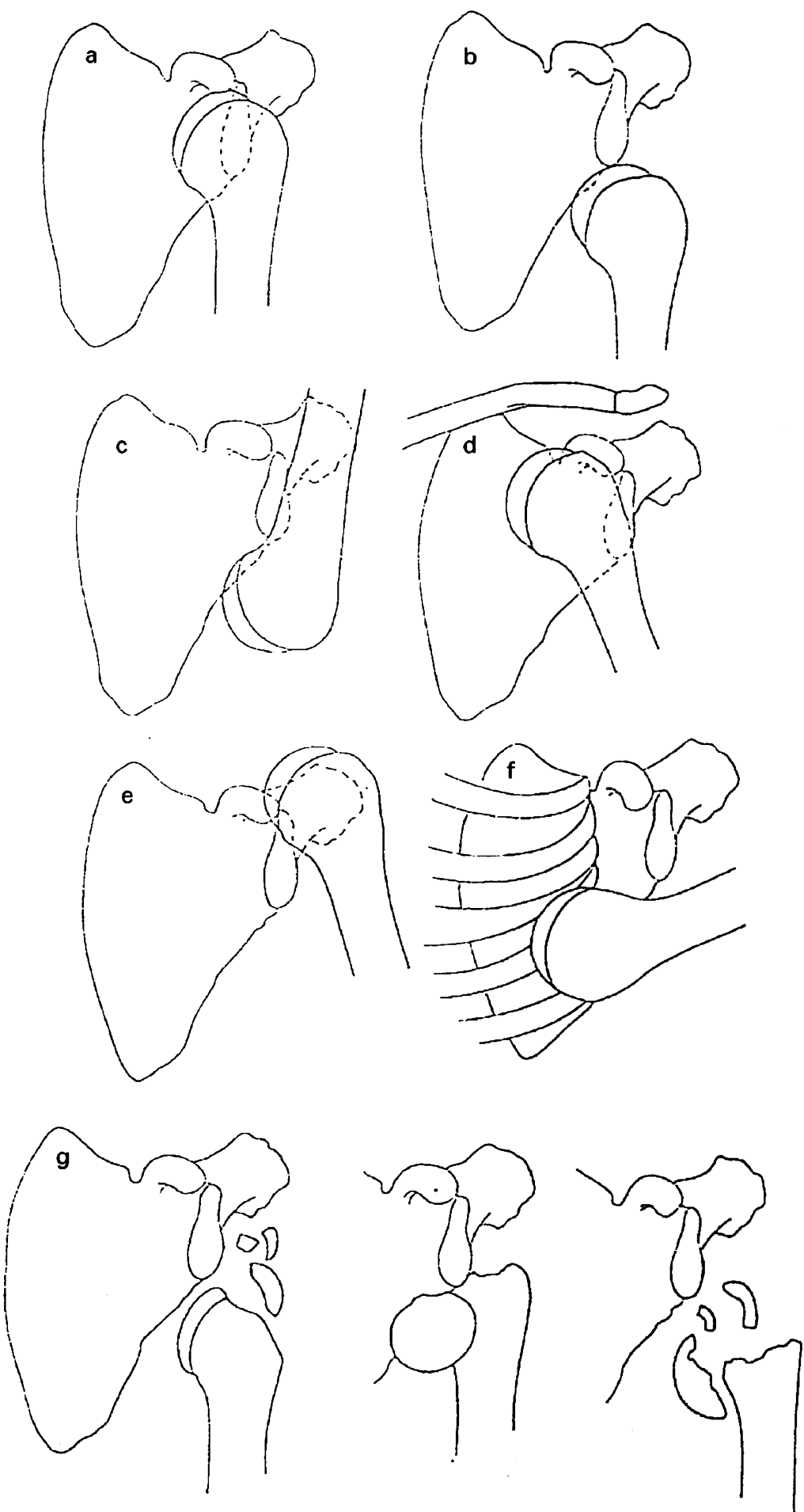

Figure 1 Types of anterior glenohumeral dislocation: (a) subcoracoid, (b) subglenoid, (c) luxatio erecta, (d) subclavicular, (e) supraglenoid, $(f)$ intrathoracic, $(g)$ fracture-dislocation. humerus, unwinds the joint capsule, ${ }^{24}$ and shortens the rotator cuff muscles which then effect a posterior pull on the humeral head. Traction, although employed in many techniques, is not necessary for reduction in a great number of cases.

Before attempting reduction, radiographic assessment of the dislocation is essential because the reduction manoeuvre of choice should be dictated by the subtype of anterior dislocation.

SUBCORACOID DISLOCATION

Subcoracoid dislocations account for $90 \%$ of anterior dislocations. ${ }^{27}$ The humeral head is wedged by the spasm of subscapularis and the other internal rotators of the humerus. This impingement causes the Hill-Sachs lesion seen on the posterolateral aspect of the humeral head in up to $40 \%$ of patients. ${ }^{6}$ The three manoeuvres most commonly used for subcoracoid dislocations are the Kocher technique, the Milch manoeuvre, and the external rotation method.

The Kocher technique is probably much older than its initial description. ${ }^{28}$ This manoeuvre has high success rates ${ }^{29}{ }^{30}$ (table 1), but has been labelled as being unphysiological, brutal, and dangerous because of its association with fractures of the surgical neck of humerus. ${ }^{31}$ Most adverse reports, however, are from the early part of this century, when anaesthetic and analgesic techniques were in their infancy. ${ }^{32} 33$ Fractures with this technique only occur when the operator forcibly tries to overcome muscle spasm, the elderly osteoporotic patient being at most risk. If resistance to reduction is met, then the patient either requires supplemental sedation/analgesia or a different reduction manoeuvre.

Many variations of the Kocher manoeuvre are used but, in his original description of the technique, Kocher described "pressing the arm, with elbow flexed, close to the side of the body, outward rotation until a resistance is encountered, elevation forward of the externally rotated arm in the sagittal plane as far as it will go, and finally slow inward rotation" (fig 2A-D). Traction was not described at any stage, ${ }^{34}$ but was added later by proponents of the technique. ${ }^{35}$ In fact, axial traction in subcoracoid dislocations serves no purpose before external rotation apart from moving the humeral head more inferiorly, thereby causing pain and inducing muscle spasm. ${ }^{36}$

There is considerable logic in the individual movements as described by Kocher. Flexion at the elbow is thought to relax the hold of the long head of biceps on the humeral head. ${ }^{37}$ Adduction of the arm moves the humeral head laterally, thereby stretching subscapularis. External rotation stretches the internal rotators further and moves the head over the glenoid rim. At this point the head may fall into position, facilitated by the pull of the rotator cuff muscles. If not, elevation of the externally rotated arm in the saggital plane presents the smallest area of the humeral head to the glenoid $^{20}$ with reduction being further aided by adduction of the externally rotated arm key movement in effecting reduction. It overcomes spasm of the internal rotators of the 
Table 1 Success rates for reduction methods

\begin{tabular}{llccr}
\hline Technique & Author & Year & $\begin{array}{l}\text { Number of } \\
\text { patients }\end{array}$ & $\begin{array}{l}\text { Success rate } \\
\text { (\%) }\end{array}$ \\
\hline Kocher & Royle & 1973 & 39 & 95 \\
Milch & Beattie & 1986 & 89 & 82 \\
& Lacey & 1952 & 18 & 100 \\
& Russell & 1981 & 76 & 89 \\
& Janecki & 1982 & 50 & 100 \\
Beattie & 1986 & 90 & 80 \\
& Johnson & 1992 & 142 & 86 \\
& Liedelmeyer & 1977 & 50 & 100 \\
& Mirick & 1979 & 85 & 81 \\
& Danzl & 1986 & 100 & 78 \\
Scapular manipulation & Thakur & 1990 & 16 & 100 \\
& Banerjee & 1990 & 44 & 86 \\
& Jeyarajan & 1991 & 42 & 95 \\
& Anderson & 1982 & 51 & 92 \\
& Kothari & 1992 & 48 & 96 \\
& McNamara & 1993 & 61 & 79 \\
\hline
\end{tabular}

across the chest before internal rotation (fig 2E).

The Milch manoeuvre was described in 1938 for subcoracoid dislocations. The operator abducts and elevates the arm while fixing the humeral head with his contralateral thumb. At the point of maximum abduction, firm pressure is exerted over the head of the humerus to effect reduction (fig 3A). Traction on the abducted arm was not described
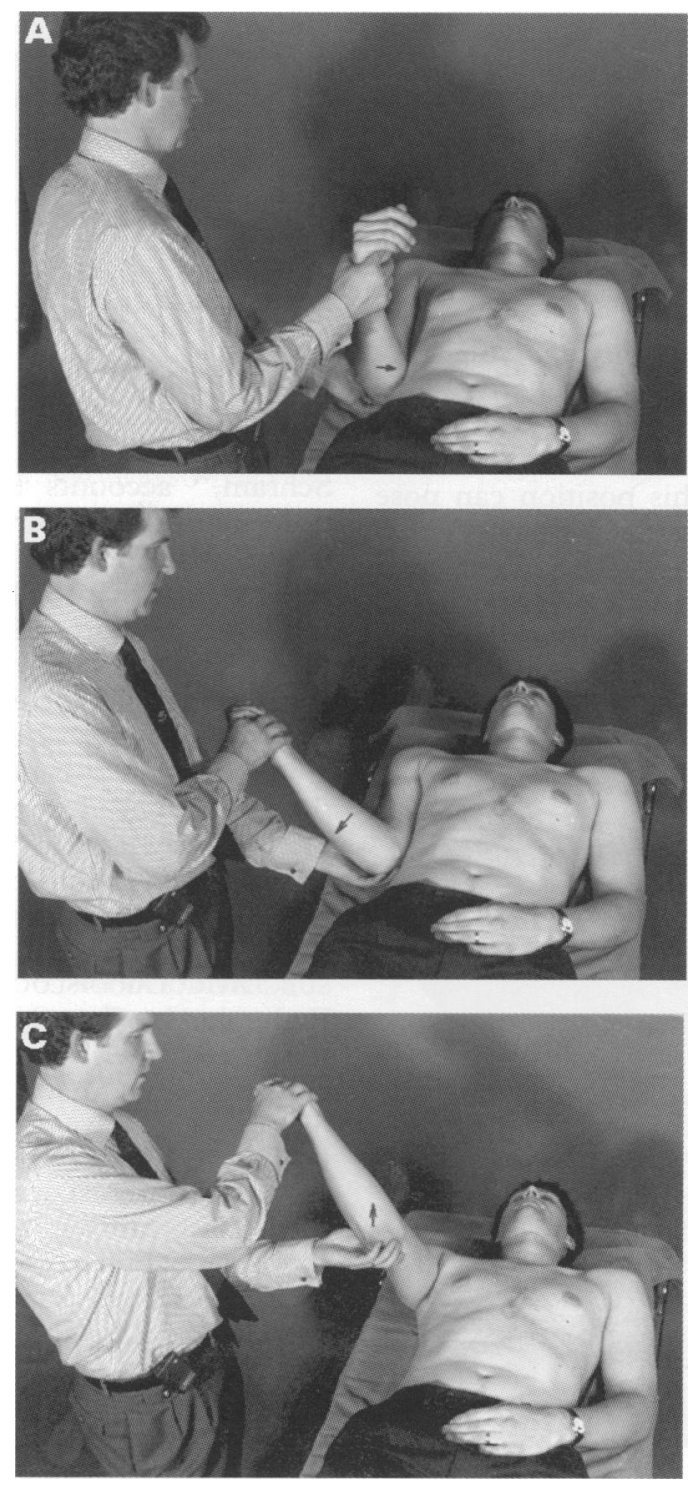

originally and has been added by other operators. ${ }^{192030}$ The theory behind this manoeuvre is that in the fully abducted position the muscles acting about the shoulder joint are aligned in the same plane and are thus not working against each other. As a result, there is less chance of causing a fracture during manipulation. It is a safe procedure with no reported complications and is thought to be relatively painless ${ }^{7030}$; however, no prospective trial to date has compared pain scores for different reduction manoeuvres based on objective assessment.

If reduction has not been successful using the standard Milch manoeuvre, one can apply traction on the abducted arm accompanied by firm pressure over the humeral head with the fingertips. The arm is then abducted while maintaining traction and pressure over the humeral head. The operator's fingers in this instance act as a fulcrum over which the humeral head can move (fig 3B).

The external rotation method, as described by Leidelmeyer, ${ }^{26}$ is essentially the initial movements of the Kocher manoeuvre, that is, adduction and external rotation with the patient in a supine position (fig $2 \mathrm{~A}$ and $\mathrm{B}$ ).
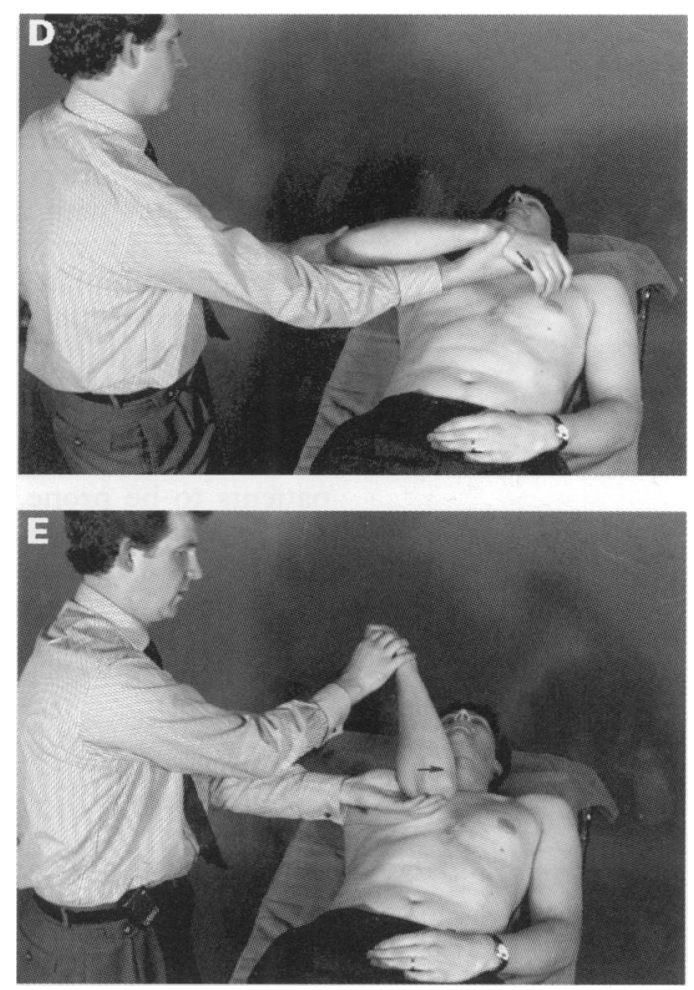

Figure 2 (A) Kocher manoeuvre; adduction with the elbow flexed. (B) Kocher manoeuvre; external rotation. (C) Kocher manoeuvre; forward elevation of the externally rotated arm. (D) Kocher manoeuvre; internal rotation. (E) Kocher manoeuvre; adduction of the externally rotated arm. 

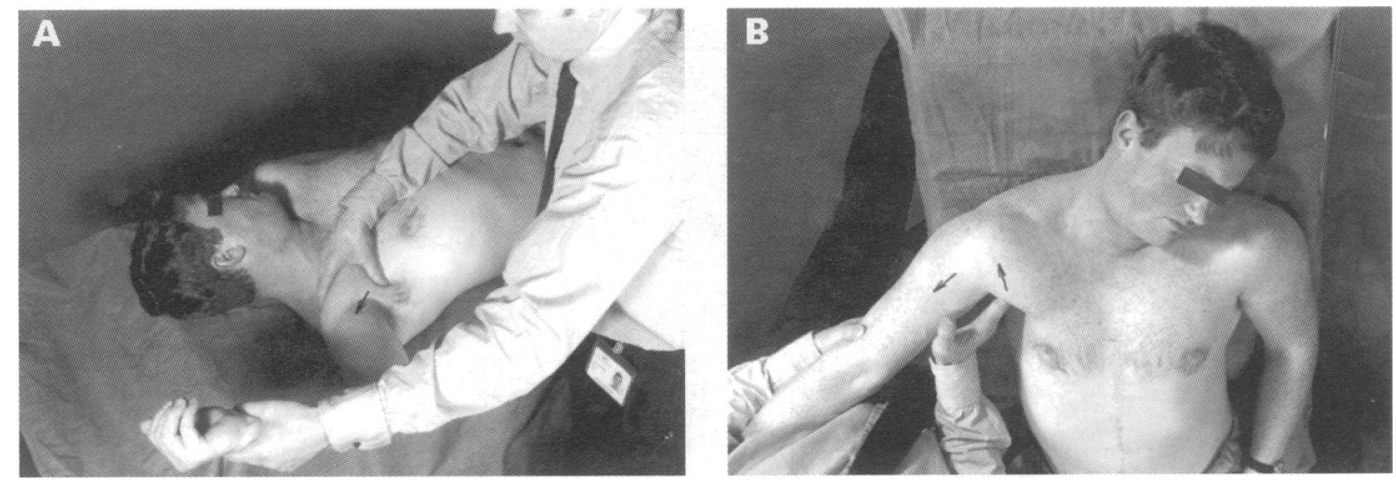

Figure 3 (A) Milch manoeuvre. (B) Traction, adduction and pressure on the humeral head.

External rotation, aided by gravity, should occur over several minutes to minimise muscle spasm. This is an atraumatic method which has achieved success rates of up to $80 \%$ for subcoracoid dislocations. ${ }^{38}{ }^{39}$ Failure to achieve reduction with this technique occurs most commonly in the elderly and may be due to absence of the pull of the rotator cuff muscles on the humeral head when there is a complete tendon tear. In one review of patients over 40 years of age with anterior dislocations, $90 \%$ had full thickness tears. ${ }^{40}$

The scapular manipulation manoeuvre has achieved popularity in north America, but is not widely used in the United Kingdom. Originally described by Bosley and Miles, ${ }^{23}$ it has high success rates. ${ }^{41-43}$ Patients are placed prone, with the affected arm hanging vertically from a trolley with a 5 or 15 pound weight attached to the wrist. After five minutes the operator manipulates the scapula by pushing its inferior angle medially (fig 4). The reduction may be facilitated by applying traction and externally rotating the arm. This technique has the disadvantage of being difficult in obese individuals and of requiring the patients to be prone. This position can pose difficulties for certain patients, particularly if they require intravenous sedation/analgesia and airway management is a priority. It has been performed in the seated ${ }^{43}$ and supine positions ${ }^{44}$ but under these circumstances it is

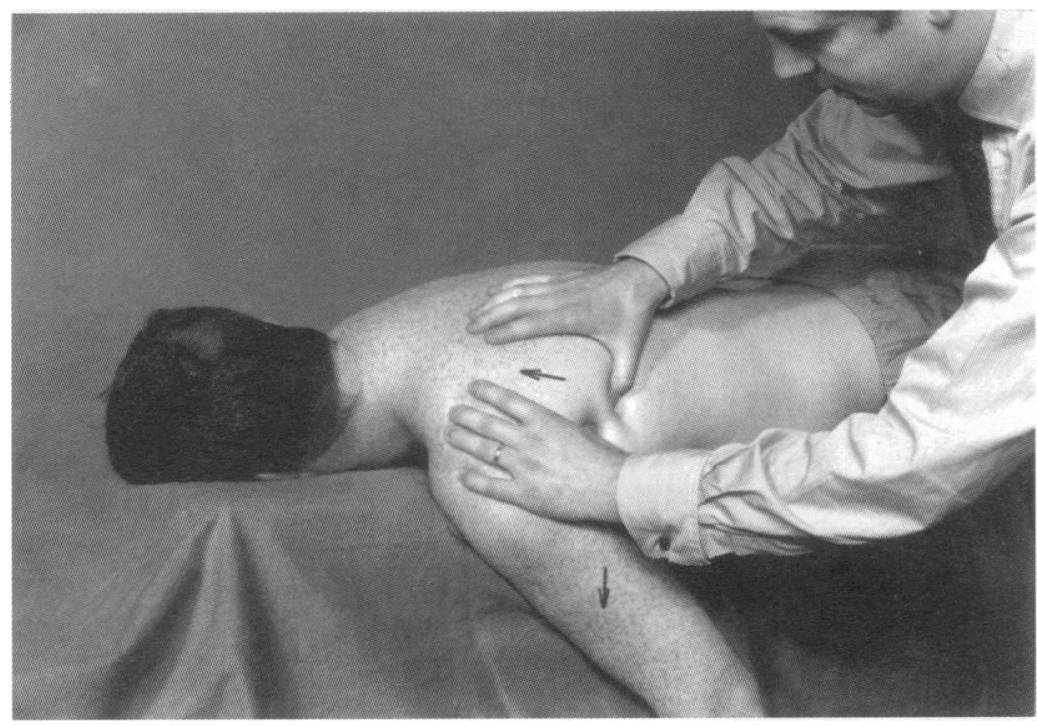

Figure 4 Scapular manipulation. recognised as being technically difficult and painful.

SUBGLENOID DISLOCATION

These dislocations often have an associated fracture of the greater tuberosity of the humerus and are seen more commonly in older patients. Because of the inferior position of the head in relation to the glenoid, traction is essential for reduction. The Hippocratic method, where the operator applies traction on the arm while providing countertraction with his foot in the patient's axilla ${ }^{45}$ (fig 5A), was thought to have been introduced specifically for subglenoid dislocations. ${ }^{27}$ Additional external rotation of the arm will facilitate reduction. Alternatively, countertraction can be employed using a sheet and an assistant (fig 5B). The Hippocratic method is reported as carrying a significant risk of neurovascular damage and thus many operators prefer to use the Milch manoeuvre with added traction.

\section{LUXATIO ERECTA}

This uncommon form of dislocation, first described in 1859 by Middledorff and Schram, ${ }^{46}$ accounts for $1 \%$ of all shoulder dislocations. ${ }^{47}$ It occurs when the humerus dislocates with the arm in full abduction and is associated with rotator cuff tears and greater tuberosity fractures in $50 \%$ of cases. ${ }^{48}$ Luxatio erecta is ideally suited for the latter movements of the Milch manoeuvre with countertraction over the shoulder assisting reduction. Considerable traction is usually required to dislodge the humeral head from under the glenoid, and the arm may have to be adducted while maintaining traction and pressure on the humeral head to effect reduction.

\section{SUBCLAVICULAR DISLOCATION}

Reduction is effected by a combination of traction and external rotation on the slightly abducted arm, that is, the Hippocratic technique.

\section{SUPRAGLENOID DISLOCATION}

Such dislocations usually result from an upward axial force applied to the flexed elbow in an adducted arm. ${ }^{17}$ They are commonly associated with rotator cuff tears, long head of biceps rupture, and fractures of the greater tuberosity, acromium, and coracoid process. Traction on the externally rotated adducted arm will usually suffice for reduction. ${ }^{49}$ 

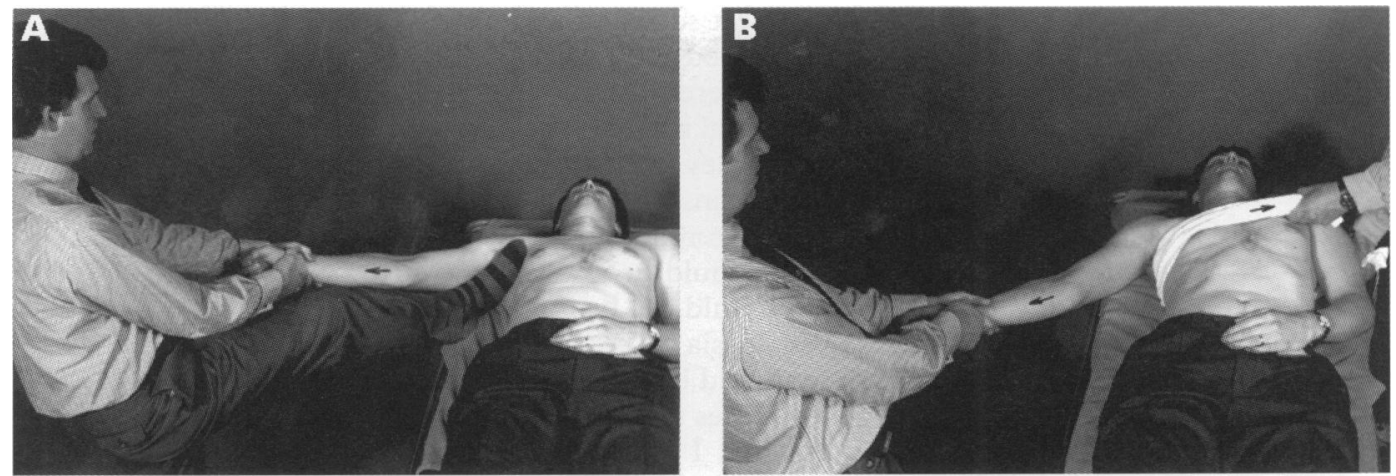

Figure 5 (A) Hippocratic technique; the foot can be used to exert pressure on the humeral head. (B) Hippocratic technique using sheet for countertraction.

INTRATHORACIC DISLOCATION

This is rare and is beyond the scope of normal A\&E practice.

FRACTURE-DISLOCATION

Classification is into three types, ${ }^{50}$ two part, three part, and four part.

\section{Two part}

A fracture of the greater tuberosity occurs in approximately $10 \%$ of dislocations and is usually associated with the humeral head in a subglenoid, low subcoracoid, or subclavicular position. The reduction manoeuvre used will depend on the position of the humeral head. Dislocations associated with a humeral neck fracture, whether displaced or not, should probably be reduced under general anaesthesia with image intensification in order to diminish the risk of neurovascular damage. Apparent two part fractures may inadvertently be converted to three part with closed reduction in $A \& E$ when undisplaced neck fractures are not seen on the original films. ${ }^{16}$ If reduction is

\section{ANTERIOR DISLOCATION}

\begin{tabular}{|c|c|c|c|}
\hline Subcoracoid & $\begin{array}{l}\text { Subglenoid/ } \\
\text { luxatio erecta }\end{array}$ & $\begin{array}{c}\text { Subclavicular/ } \\
\text { supraglenoid }\end{array}$ & Intrathoracic \\
\hline$\downarrow$ & $\downarrow$ & $\downarrow$ & $\downarrow$ \\
\hline External rotation & Milch & Hippocratic & $\begin{array}{c}\text { Refer } \\
\text { ortho/thoracics }\end{array}$ \\
\hline$\downarrow$ failure & $\downarrow$ failure & $\downarrow$ failure & \\
\hline Kocher & Hippocratic & Refer ortho & \\
\hline$\downarrow$ failure & $\downarrow$ failure & & \\
\hline Milch & Refer ortho & & \\
\hline
\end{tabular}

$$
\begin{gathered}
\downarrow \text { failure } \\
\text { Hippocratic } \\
\downarrow \text { failure }
\end{gathered}
$$

Refer ortho

\begin{tabular}{ll}
\multicolumn{2}{c}{ Fracture-dislocation } \\
$\begin{array}{l}\text { Greater tuberosity } \\
\text { alone }\end{array}$ & $\begin{array}{l}\text { Fracture surgical } \\
\text { neck or } 3 / 4 \text { part }\end{array}$ \\
$\downarrow$ & $\downarrow$ \\
$\begin{array}{l}\text { Reduction method } \\
\text { depends upon } \\
\text { position of humeral } \\
\text { head (see above) }\end{array}$ & Refer ortho
\end{tabular}

attempted in A\&E, external rotation should not form part of the procedure. Reduction may be effected by traction and pressure over the humeral head.

\section{Three part}

Open reduction and internal fixation is the treatment of choice. ${ }^{51}$ Avascular necrosis of the humeral head may ensue but, it may be averted by the blood supply to the head from the anterior capsule and subscapularis. If the displacement is severe a hemiarthroplasty is indicated.

\section{Four part}

These should all be managed by hemiarthroplasty. ${ }^{51}$

\section{Failed reduction}

The majority of anterior glenohumeral dislocations can be reduced in A\&E. There are, however, a few cases where reduction cannot be achieved despite the use of several manoeuvres and adequate sedation and analgesia. Delayed presentations or very muscular individuals frequently fall into this group. Reductions may also be impeded by interposed biceps tendon, ${ }^{52-54}$ subscapularis, ${ }^{55}$ labrum, or a greater tuberosity fragment. ${ }^{56}$ General anaesthesia is indicated for these "failures."

\section{Aftercare}

Successful reduction should be confirmed radiologically and the neurovascular status in the affected arm should be rechecked. Patients can then be discharged in a collar and cuff with a body bandage and suitable oral analgesia. Patients who have received intravenous sedation/analgesia should be monitored by nursing staff in $A \& E$ until they are alert and can walk unaided, and before their discharge to the care of a responsible adult they should be alerted to the risks of driving, working machinery, and drinking alcohol in the subsequent 24 hours. Follow up within a few days in the orthopaedic clinic is appropriate.

\section{Conclusion}

A\&E doctors should tailor their approach to a dislocated shoulder depending on the requirements of individual patients. No one technique will work for all dislocations. The two most important factors determining a successful reduction are the relief of pain and muscle 
spasm and the correct selection and execution of a reduction manoeuvre. Before reduction, patients should be offered Entonox for relief of their pain. After several minutes they should be reassessed and, if they are still significantly uncomfortable and insufficiently relaxed to allow an atraumatic reduction, intravenous sedation/analgesia should be given. Resistance during reduction should not be met with force. Supplemental analgesia or a different reduction manoeuvre should be employed. The flow diagram (fig 6 ) outlines the sequence of reduction manoeuvres that I would recommend in the approach to anterior dislocation reduction.

1 Kazar B, Rolevsky E. Prognosis of primary dislocation of the shoulder. Acta Orthop Scand 1969;40:216-24.

2 Kroner K, Lind T, Jensen J. The epidemiology of shoulder dislocations. Arch Orthop Trauma Surg 1989;108:288-90.

3 Riebel GD, McCabe JB. Anterior shoulder dislocation: review of reduction techniques. Am J Emerg Med 1991;9 180-8.

4 Mc Laughlin HC, Cavallaro WN. Primary anterior dislocation of the shoulder. Am J Surg 1950;80:615-21.

5 DePlama AF, Flannery GF. Acute anterior dislocation of the shoulder. Am J Sports Med 1973;1:6-15.

6 Post M. The shoulder: surgical and non-surgical management. Philadelphia: Lea and Febiger, 1978:429-56.

7 Johnson G, Hulse W, McGowan A. The Milch technique for reduction of anterior shoulder dislocations in an accident and emergency department. Arch Emerg Med 1992;9: 40-3.

8 Banerjee A. Is anaesthesia necessary for reducing shoulder dislocation? Arch Emerg Med 1990;7:240

9 Russell JA, Holmes EM, Keller DJ, Vargas JH. Reduction of acute anterior shoulder dislocations using the Milch acute anterior shoulder dislocations

10 Edeland HG, Stefansson T. Block of the suprascapula nerve in reduction of acute anterior shoulder dislocation: case reports. Acta Anaesth Scand 1973;17:46-9.

11 Gleeson AP, Graham CA, Jones I, Beggs I, Nutton RW Comparison of intra-articular lignocaine and a suprascapular nerve block for acute anterior shoulder dislocation. Injury 1997;28:141-2.

12 Underhill TJ, Wan A, Morrice $M$. Interscalene brachia plexus blocks in the management of shoulder dislocations. Arch Emerg Med 1989;6:199-204.

13 Lippit SB, Kennedy JP, Thompson TR. Intra-articular lidocaine versus intravenous analgesia in the reduction of dislocated shoulders. Orthop Trans 1991;15:804

14 Matthews DE, Roberts T. Intraarticular lidocaine versus intravenous analgesic for reduction of acute anterior shoulder dislocations. a prospective randomised study. Am J Sports Med 1995;23:54-8.

15 The Royal College of Surgeons of England. Guidelines for sedation by non-anaesthetists. London: RCS, 1993.

16 Ferkel RD, Hedley AK, Eckardt JJ. Anterior fracturedislocations of the shoulder: pitfalls in treatment. J Traum dislocations of the

17 Stimson LA. An easy method of reducing dislocations of the shoulder and hip. Med Rec 1900;57:356-7.

18 Rollinson PD. Reduction of shoulder dislocations by the hanging method. S Afr Med J 1988;73:106-7.

19 Lacey T, Crawford HB. Reductions of dislocations on the shoulder joint by means of the Milch abduction technique. J Bone Joint Surg Am 1952;34A:108-9.

20 McNair TJ. A clinical trial of the "hanging arm" reduction of dislocation of the shoulder. J R Coll Surg Edinb 1957;3. 47-53.

21 Pick RY. Treatment of the dislocated shoulder. Clin Orthop 1977;123:76-7.

22 Lippert FG. A modification of the gravity method of reducing anterior shoulder dislocations. Clin Orthop 1982;165: 259-60.

23 Bosley RC, Miles JS. Scapular manipulation for reduction of anterior inferior dislocations: a new procedure. Paper read before the American Association of Osteopathic Colleges, 1979.

24 Kocher T. Eine neue reductionsmethode fur schultetrverrenkung. Berliner Klin Wehnschr 1870;7:101-5.
25 Milch H. Treatment of dislocation of the shoulder. Surgery 1938;3:732-40.

26 Leidelmeyer R. Reduced! A shoulder subtly and painlessly. J Emerg Med 1977;9:223-4.

27 Plummer D, Clinton J. The external rotation method for reduction of acute anterior shoulder dislocation. Emerg Med Clin North Am 1989;7:165-75.

28 Hussein MK. Kocher's method is 3,000 years old. J Bone Joint Surg Br 1968;50B:669-71.

29 Royle G. Treatment of acute anterior dislocation of the shoulder. Br J Clin Pract 1973;27:403-4.

30 Beattie TF, Steedman DJ, McGowan A, Robertson CE. A comparison of the Milch and Kocher techniques for acute anterior dislocation of the shoulder. Injury 1986;17:34952.

31 Milch $\mathrm{H}$. The treatment of recent dislocations and fracturedislocations of the shoulder. J Bone Joint Surg Am 1949;31A:173-80.

32 Nash J. The status of Kocher's method of reducing recent anterior dislocations of the shoulder. J Bone Joint Surg Am 1934;16A:535-44.

33 Watson-Jones R. Fractures and joint injuries, vol 2, 3rd ed. Baltimore: Williams and Wilkins, 1943:460-1.

34 Jeyarajan R, Cope AR. Anaesthesia for reduction of anterior dislocations of the shoulder. Arch Emerg Med 1992;9:72.

35 Watson-Jones R. Fractures and joint injuries, vol 2, 6th ed. Edinburgh: Churchill Livingstone, 1982:550-4.

36 Thakur AJ, Narayan R. Painless reduction of shoulder dislocation by Kocher's method. J Bone Joint Surg Br 1990;72B:524.

37 Cubbins WR, Callahan JJ, Scuderi CS. The reduction of old or irreducible dislocations of the shoulder joint. Surg or irreducible dislocations of

38 Mirick MJ, Clinton JE, Ruiz E. External rotation method of shoulder dislocation reduction. J Am Coll Emerg Phys 1979;8.528-31.

39 Danzl DF, Vicario SJ, Gleis GL, Yates JR, Parks DL. Closed reduction of anterior subcoracoid shoulder dislocation: evaluation of an external rotation method. Orthop Rev 1986;15:311-5.

40 Hawkins RJ, Bell RH, Hawkins RH, Koppert GJ. Anterior dislocation of the shoulder in the older patient. Clin Orthop 1986;206:192-8.

41 Anderson D, Zvirbulis R, Ciullo J. Scapular manipulation for reduction of anterior shoulder dislocations. Clin Orthop 1982;164:181-3.

42 Kothari RU, Dronen SC. Prospective evaluation of the scapular manipulation technique in reducing anterior scapular manipulation technique in reducing anterior

43 McNamara RM. Reduction of anterior shoulder dislocations by scapular manipulation. Ann Emerg Med 1993;22: tions by

44 Doyle WL, Rager T. Use of the scapular manipulation method to reduce an anterior dislocation of the shoulder in the supine position. Ann Emerg Med 1996;27:92-4.

45 Rockwood CA, Green DP. Fractures, 2nd ed. Philadelphia JB Lippincott, 1984:746-51.

46 Khan ML, Bade HA, Stein I. Body surfing as a cause of luxatio erecta. Orthop Rev 1987;16:729-33.

47 Downey EF, Curtis DJ, Brower AC. Unusual dislocations of the shoulder. Am J Radiol 1983;140:1207.

48 Mallon WJ, Basset FH, Goldner RD. Luxatio erecta: the inferior glenohumeral dislocation. J Orthop Trauma 1990; 4:19-24.

49 Farrugia PD. Superior glenohumeral dislocation. a case report. Injury 1985;16:489-90.

50 Neer CS. Displaced proximal humeral fractures: Part I. Classification and evaluation. J Bone Joint Surg Am 1970 52A:1077-89.

51 Neer CS. Displaced proximal humeral fractures: Part II. Treatment of three-part and four-part displacement. J Bone Joint Surg Am 1970;52A:1090-103.

52 Henderson RS. Fracture-dislocation of the shoulder with interposition of the long head of biceps. J Bone Joint Surg Br 1952;34B:240-41.

53 Janecki CJ, Barnett DC. Fracture-dislocation of the shoulder with biceps tendon interposition. J Bone Join Surg Am 1979;61A:142-3.

54 Inao S, Hirayama T, Takemitsu Y. Irreducible acute anterior dislocation of the shoulder: interposed bicipital tendon. Bone Joint Surg Br 1990;72B:1079-80.

55 Bridle SH, Ferris BD. Irreducible anterior dislocation of the shoulder: interposed scapularis. J Bone Joint Surg Br 1990; 72B:1078-9.

56 Seradge $\mathrm{H}$, Orme G. Acute irreducible anterior dislocation of the shoulder. J Trauma 1982;22:330. 